\title{
Tobacco Use and Oral Health Status among Adolescents in an Urban Slum, Gurugram
}

\author{
VISHESH YADAV', SHALINI RAY², PRIYANKA SACHDEVA ${ }^{3}$, ANKUR BHAGAT4
}

INTRODUCTION: Tobacco use is one of the main risk factors for number of chronic diseases including cardiovascular diseases, lung cancer and oral cancer. Tobacco epidemic is one of the public health threats killing nearly six million people yearly. Tobacco use also contributes to poor oral health causing staining, bad breath and tooth decay. Different studies in India are suggestive of upward trend in use of tobacco even in adolescents.

OBJECTIVES: To find the prevalence of tobacco use among adolescents in an urban slum and to assess the oral health status among them. METHODOLOGY: This cross sectional study was done as a part of oral health assessment camp conducted in an urban slum. All adolescents attending the camp were recruited in the study after due informed consent, the final sample size being 130.

RESULTS: The overall tobacco use among adolescents was found to be $95.8 \%$ adolescent boys and $27.6 \%$ among adolescent girls. The most common reasons cited for tobacco use were peer pressure followed by parent's influence. Smokeless tobacco (dry tobacco, lime, guthka) was consumed by $39.13 \%$ boys and $19 \%$ girls. Smoking was prevalent among $16.7 \%$ boys and $8.6 \%$ girls. However $41.7 \%$ adolescent boys consumed both forms of tobacco. Prevalence of dental caries was high in both boys $(77.7 \%)$ and girls $(55.2 \%)$. The presence of tartar was found in $47.3 \%$ boys and $22.4 \%$ girls. Bleeding gums was found in more no. of girls $(29.3 \%)$ as compared to boys $(25 \%)$. The other morbidities found on examination were ulcer ( $16.7 \%$ boys and $3.5 \%$ girls), Oral submucous fibrosis was seen in $27.8 \%$ boys and $3.5 \%$ girls.

CONCLUSION: Appropriate intervention is required as adolescence is a tender period where these risk factors like tobacco consumption and oral hygiene could be modified by awareness and counselling.

KEYWORDS: Tobacco, Adolescents, Oral Hygiene

\section{INTRODUCTION}

Tobacco is the most usually manhandled sedate on the planet. Tobacco smoking and chewing are the second major causes of death in the world. The tobacco loss of life is relied upon to twofold by 2025 from the present 5 million passing (approx). At each 6.5th second, a man bites the dust on account of a tobacco related ailment, all around. ${ }^{1}$ The topic for 'World No Tobacco Day-2008'Tobacco Free Youth centres around young people and required the development of youth gatherings and mindfulness building. ${ }^{2}$ The most powerless time for commencement of tobacco use in India is amid youthfulness and early adulthood i.e., in the age gathering of 15 -24 years. ${ }^{3}$ Centring the essential counteractive action among youths is fundamental. Adolescence is the stage of transition when they are involved in experimenting with various risk behaviors such as smoking, risky sexual behavior and tobacco, alcohol and drug use. In the meantime, it might be less demanding to incorporate solid practices at a youthful age as opposed to change the conduct at later ages or after the beginning of a sickness. ${ }^{4}$ Maintaining oral hygiene is shockingly a standout amongst the most disregarded practice among youth particularly in the underprivileged provincial and urban ghetto networks. The present study was led to discover the predominance of tobacco utilization among young people in urban slum and to assess oral health status among them.

\section{MATERIALS AND METHOD}

The present cross sectional examination was directed among the young people residing in urban slum Basai which is catered by the urban health training centre, SGT Medical College, Gurugram. All adolescents (10-19 years) attending the dental camps organized at urban slum were approached for participation in the study. Those adolescents who gave written informed consent for participation were recruited. In case of adolescents below 18 years, consent was acquired from the accompanying guardian. A total of 130 adolescents were recruited. A predesigned pretested organized poll was utilized for information accumulation. The information which was identified with their socio-statistic qualities and tobacco utilization was gathered from the adolescents. The socioeconomic status of the investigation subjects was resolved according to the modified B.G. Prasad's classification. All participant were subjected to dental examination in a well-lit area. The statistical analysis was completed by using percentage and the Chi square test. 


\section{RESULTS AND DISCUSSION}

Table 1 demonstrates the socio demographic distribution of study participants. About 55.38\% adolescents were boys and rest $44.6 \%$ were girls. Around $49.23 \%$ adolescents were $14-16 y e a r s$ age i.e mid adolescence. Majority $43 \%$ adolescents were illiterate. About $75.4 \%$ resided in a nuclear family and rest $24.6 \%$ belonged to joint family. The greater part of the adolescents belonged to class III and class IV socioeconomic status.

Table 2 demonstrates the prevalence of tobacco utilization among adolescents. In the study area, 95.8\% adolescent boys and $27.6 \%$ adolescent girls consumed tobacco. Smokeless tobacco (dry tobacco, lime, guthka) was consumed by $39.13 \%$ boys and $19 \%$ girls. Smoking was prevalent among $16.7 \%$ boys and $8.6 \%$ girls. However $41.7 \%$ adolescent boys expended both forms of tobacco. The prevalence of tobacco utilization in teenagers was $65.3 \%$, which is high. Similar results were found in study conducted by Surekha Kishore et al. ${ }^{5}$ and Dongare AR et al. ${ }^{6}$ Sinha DN et al ${ }^{7}$ detailed that $75.3 \%$ of the understudies who were matured 13 to 15 years in Mizoram were tobacco clients. Youthful young men devoured both smokeless and smoke type of tobacco, though the young ladies expended the smokeless structures as it were.

Table 3 demonstrates the relationship between tobacco consumption and gender. The prevalence of tobacco utilization was higher among adolescent boys (95.8\%) as compared to adolescent girls (27.8\%). This difference was observed to be factually significant $(\mathrm{p}<0.0001)$. This finding is practically identical with different investigations. ${ }^{8,9,10,11}$ The prevalence found in our study was significantly higher than the rates of the nationwide survey conducted in 2009 which reported prevalence of 9.5 percent, ${ }^{12}$ and a Kerala study in 2011 announcing 9.8 for every penny prevalence. ${ }^{13}$ Further, the prevalence was much lower than discoveries from examines from Western nations which indicated changing predominance in the vicinity of 20 and 67 for each penny. ${ }^{14,15}$

Table 4 shows the oral wellbeing status of adolescents. On examination, it was found that the prevalence of dental caries was high in both boys $(77.7 \%)$ and girls $(55.2 \%)$. The presence of tartar was found in $47.3 \%$ boys and $22.4 \%$ girls. Bleeding gums was found in more no. of girls $(29.3 \%)$ as compared to boys $(25 \%)$. The other morbidities found on examination were ulcer ( $16.7 \%$ boys and $3.5 \%$ girls), Oral submucous fibrosis was seen in $27.8 \%$ boys and $3.5 \%$ girls. Most extreme oral wellbeing and dental issues were seen among male as contrast with the female youths.

The relationship between dental caries and tobacco utilization was observed to be factually significant ( $\mathrm{p}<0.0001$ ) (Table 5). About $84.2 \%$ adolescents consuming tobacco had dental caries as compared to only $\mathbf{2 2 . 8 \%}$ adolescents who did not consume tobacco. One of the principle explanations behind the relationship between smokeless tobacco and dental caries is the nearness of high measure of different sugars and sweeteners included amid the business assembling of smokeless tobacco items. ${ }^{16}$

Fig.1 shows the different reasons cited by adolescents for consuming tobacco. About $52 \%$ adolescents initiated tobacco due to peer pressure, $14.5 \%$ reported influence by relatives, $7.5 \%$ adolescents said tobacco consumption provides social status and $26 \%$ opined tobacco consumption was fashionable. Peer pressure is a vital deciding element for commencement of tobacco use among kids and young people. Companion weight is a critical deciding component for inception of tobacco use among kids and young people.

\section{CONCLUSION}

The findings in the study suggest that tobacco use is still an important risk behavior among adolescents. Influence of adolescent is multifactorial. A portion of these are peer pressure, experimentation amid young, and simple access to such items alongside identity factors. At the same time awareness about oral hygiene should be encouraged among adolescents, Though the significance of oral cleanliness and tobacco abuse is well-known, the need of awareness programs, visit screening camps ought to be underlined by public health 
professionals.

\section{REFERENCES}

1. Abdullah AS, Husten CG. Promotion of smoking cessation in developing countries: a framework for urgent public health interventions. Thorax 2004; 59/7:623-30.

2. World No Tobacco Day 2008. Available at: http://www.who.int/entiti/

tobacco/wntd/2008/en/index.html. Accessed $10^{\text {th }}$ July 2010.

3. Reddy KS, Gupta PC, editors. Report of tobacco control in India. New Delhi: Ministry of Health and Family Welfare, Government of India; 2004.

4. Selvan M S, Kurpad A V. Primary prevention: Why focus on children and young adolescents? Indian J Med Res 2004; 120:511-518.

5. Kishore S, Garg BS, Muzammil K. Tobacco addiction amongst adolescents in the rural areas of the Wardha district. JK Science 2007; 9/2:79-82. 6. Dongre AR, Deshmukh PR, Murali N, Garg BS.Tobacco consumption among adolescents in rural Wardha: Where and how should tobacco control focus its attention? Indian Journal of Cancer. 2008; 45/3:100-6.

7. Sinha DN, Gupta PC, Pednekar MS. Tobacco use among students in the eight north-eastern states of India. Indian Journal of Cancer 2003; 40/2:4359.

8. MOHP/WHO. Nepal 2011 country report GYTS \& GSPS. Kathmandu: MOHP; 2011.

9. Pradhan PMS, Niraula SR, Ghimire A, et al. Tobacco use and associated factors among adolescent students in Dharan, Eastern Nepal: a cross-sectional questionnaire survey. BMJ Open. 2013;3:eoo2123.doi: 10.1136/bmjopen-2012-002123. 10. Sreeramareddy CT, Kishore P, Paudel J, et al. Prevalence and correlates of tobacco use amongst junior collegiate in twin cities of western Nepal: a cross-sectional, questionnaire-based survey. BMC Public Health. 20o8;8:97. doi: 10.1186/1471-2458-8-

97.

11. Hussain, Abdul Satar Prevalence and determinants of tobacco use among Iraqi adolescents: Iraq GYTS 2012. Tob Induc Dis. 2013;11:14. doi: 10.1186/1617-9625-11-14.

12. Gajalakshmi V, Kanimozhi CV. A survey of 24,0oo students aged 13-15 years in India: Global
Youth Tobacco Survey 2006 and 2009. Tob Use Insights. 2010;3:23-31.

13.Philip PM, Neetu AP, Binukumar B, Satheesan B. Evaluation of a tobacco control programme to reduce tobacco use among school children in Kerala. Asian Pac J Cancer Prev. 2013;14:3455-9.

14. Johnston LD, O'Malley PM, Miech RA, Bachman JG, Schulenberg JE. Monitoring the future national results on drug use: 1975-2013: Overview, key findings on adolescent drug use. Ann Arbor: Institute for Social Research, The University of Michigan; 2014.

15. Fielding JE. Smoking and women: tragedy of the majority. N Engl J Med. 1987;317:1343-5.

16. Vellappally S, Fiala Z, Smejkalova J, Jacob V, Shriharsha P. Influence of tobacco use in dental caries development, Cent Eur J Public Health 2007; 15 (3): 116-21. 
Source of support: Nil, Conflict of interest: None declared

\section{Cite this article as:}

Yadav V, Ray S, Sachdeva P, Bhagat A. Tobacco Use and Oral Health Status among

Adolescents In An Urban Slum, Gurugram. Int Healthcare Res J 2018;2(4):98-102. doi:

10.26440/IHRJ/o2_04/184

\section{AUTHOR AFFILIATIONS:}

1. Senior Lecturer, Department of Oral Medicine and Radiology, Eklavya Dental College and Hospital, Kotputli, Rajasthan

2. Assistant Professor, Department of Community Medicine, Faculty of Medical sciences, SGT University, Gurugram, Haryana.

3. PG Resident, Department of Community Medicine, Faculty of Medical sciences, SGT University, Gurugram, Haryana.

4. Senior Lecturer, Department of Oral Medicine and Radiology, Rayat Bahra Dental College and Hospital, Mohali, Punjab.

\section{Corresponding Author:}

Dr. Vishesh Yadav

Senior Lecturer

Department of Oral Medicine and Radiology

Eklavya Dental College and Hospital, Kotputli

Rajasthan
For article enquiry/author contact details, e-mail at: manuscriptenquiry.ihri@gmail.com

\section{LEGENDS}

\begin{tabular}{|c|c|c|c|}
\hline AGE & $\begin{array}{l}\text { ADOLESCENT } \\
\operatorname{BOYS}(\mathbf{n}=72)\end{array}$ & $\begin{array}{l}\text { ADOLESCENT GIRLS } \\
(n=58)\end{array}$ & $\begin{array}{l}\text { TOTAL } \\
(\mathrm{N}=130)\end{array}$ \\
\hline 10-13years & 26 & 12 & $38(29.23 \%)$ \\
\hline 14-16years & 27 & 37 & $64(49.23 \%)$ \\
\hline 17-19years & 19 & 9 & $28(21.54 \%)$ \\
\hline \multicolumn{4}{|l|}{ EDUCATION STATUS } \\
\hline illiterate & 35 & 21 & $56(43 \%)$ \\
\hline Primary & 15 & 17 & $32(24.6 \%)$ \\
\hline Secondary & 17 & 7 & $24(18.46 \%)$ \\
\hline High school and above & 05 & 13 & $18(13.8 \%)$ \\
\hline \multicolumn{4}{|l|}{ FAMILY TYPE } \\
\hline Nuclear & 61 & 37 & $98(75 \cdot 4 \%)$ \\
\hline Joint & 11 & 21 & $32(24.6 \%)$ \\
\hline \multicolumn{4}{|l|}{ Socioeconomic status } \\
\hline Class I & 7 & 10 & $17(13 \%)$ \\
\hline Class II & 21 & 14 & $35(26.9 \%)$ \\
\hline Class III & 18 & 18 & $36(27.7 \%)$ \\
\hline Class IV & 21 & 6 & $27(20.7 \%)$ \\
\hline Class V & 5 & 10 & $15(11.5 \%)$ \\
\hline
\end{tabular}

Table 1. Sociodemographic Profile of Adolescent Participants 




$27(39.13 \%)$
$12(16.7 \%)$
$30(41.7 \%)$
$69(95.8 \%)$

$11(19 \%)$

$05(8.6 \%)$

o

$16(27.6 \%)$

Table 2. Pattern of Tobacco Consumption among Participants

\begin{tabular}{|c|c|c|}
\hline \multicolumn{2}{|c|}{ Adolescent boys $(\mathrm{n}=\mathbf{7 2})$} & Adolescent girls $(\mathrm{n}=58)$ \\
\hline Tobacco consumption & $\mathbf{6 9}(\mathbf{9 5 . 8} \%)$ & $\mathbf{1 6}(\mathbf{2 7 . 5 8})$ \\
\hline No tobacco consumption & $\mathbf{0 3}(\mathbf{4 . 2} \%)$ & $\mathbf{4 2}(\mathbf{7 2 . 4 \% )}$ \\
\hline
\end{tabular}

Table 3. Association between Tobacco Consumption and Gender

\begin{tabular}{|c|c|c|}
\hline Oral Health status & Adolescent $\operatorname{Boys}(n=72)$ & Adolescent Girls $(n=58)$ \\
\hline Dental caries & $56(77.7 \%)$ & $32(55.2 \%)$ \\
\hline Tartar & $34(47 \cdot 3 \%)$ & $13(22.4 \%)$ \\
\hline Plaque & $12(16.7 \%)$ & о3 $(5.17 \%)$ \\
\hline Bleeding gums & $18(25 \%)$ & $17(29 \cdot 3 \%)$ \\
\hline Ulcer & $12(16.7 \%)$ & $02(3.5 \%)$ \\
\hline Fibrosis & $20(27.8 \%)$ & $02(3.5 \%)$ \\
\hline Other & $14(19.5 \%)$ & $08(13.8 \%)$ \\
\hline
\end{tabular}

Table 4. Oral Health Status of Adolescents

\begin{tabular}{|c|c|c|}
\hline & Dental caries present & Dental caries absent \\
\hline Tobacco consumption & $80(84.2 \%)$ & $15(15.8 \%)$ \\
\hline No tobacco consumption & $08(22.8 \%)$ & $27(77.2 \%)$ \\
\hline
\end{tabular}

Table 5. Association between tobacco consumption and dental caries

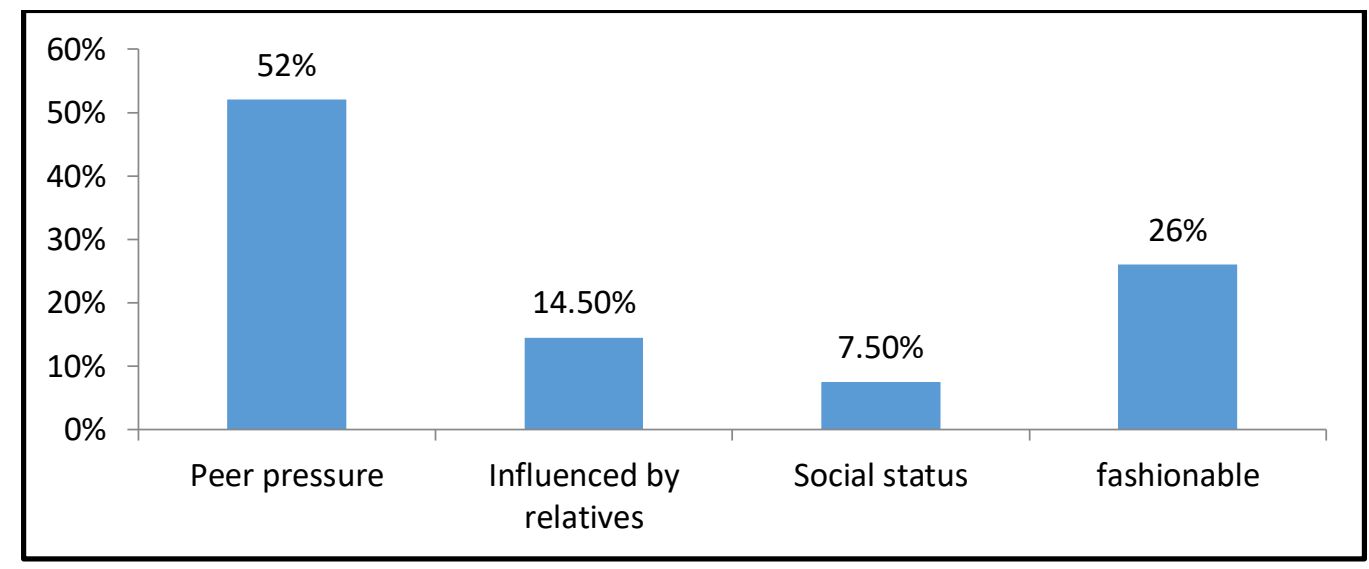

Figure 1. Reasons Cited Among Adolescents for Tobacco Consumption 